\title{
A construção curricular na sala de aula
}

\author{
Katia Maria Abud
}

\section{RESUMO}

Os relatórios dos estagiários da disciplina Metodologia do Ensino de História trazem informações sobre a sala de aula e a atuação dos professores que os recebem. Tais informações permitem que se perceba como os professores elaboram seu currículo próprio, elaborando conteúdos e métodos de ensino, que fogem aos indicados pelos órgãos públicos responsáveis pela área de educação. Ao distinguir a atuação de professores cuja formação se realizou em instituições de diferentes caracteres, os relatórios são importante fonte para que se analise a força que tem a formação

Palavras-chaves: ensino de história, formação de professores, estágio

A atuação dos professores em geral, e de História em particular, tem sido objeto de diferentes estudos, entre os pesquisadores da área da Educação e entre os pesquisadores de Ensino de História, ou da Educação Histórica, como o campo vem sendo chamado. ${ }^{1}$ A grande maioria desses estudos desenvolve concepções que jogam sobre o trabalho do professor a responsabilidade sobre a qualidade do ensino da disciplina e desconhece a interação entre cotidiano escolar e a sala de aula. É verdade que se reconhece que, se no dia a dia, o problema da qualidade de ensino pode ser identificada, de uma forma visível, à formação do professor, suas concepções a respeito da disciplina e seus compromissos políticos, estudiosos apontam também as políticas públicas como responsáveis pelos elementos que levam a tal desempenho como responsáveis

\footnotetext{
Professora de Metodologia do Ensino de História da Faculdade de Educação da Universidade de São Paulo.

1 Veja-se, por ex. LEE, Peter. Walking backward into tomorrow. Historical conscieousness understanding history. History in education. Unit School of Arts and Humanities. University of London Institute of Education. Paper given at Annual Meeting of American Research Association, New Orleans, 2002; BARCA, I. A educação histórica na sociedade de informação. O Ensino de História. Publicação Quadrimensal. Boletim da APH, n. 19/20, p. 35-42, fev. jun. 2001.
} 
por ele. Por outro lado, nos anos 90 instituiu-se um modelo de docente que se qualificou como "descentralizado, pragmático, construtivista, participativo, colaborativo" (POPKEWITZ, 1998) ${ }^{2}$, isto é um docente capaz de construir conhecimento por si mesmo. Esperava-se que assim ele atendesse aos propósitos dos órgãos dirigentes da educação e ao mesmo tempo construísse sua identidade profissional.

Muitas das medidas de políticas públicas implementadas a partir das reformas educativas em curso no Brasil se justificam e buscam seus fundamentos na falta de qualidade do processo educativo, na deterioração dos conhecimentos do professor e no "atraso" dos conteúdos a ser ensinados. Esse tipo de avaliação é realizado, dentro de parâmetros estabelecidos pelo sistema econômico predominante, no qual a educação aparece como um dos carros chefes de um novo desenvolvimento capitalista. De um modo geral, essas análises tendem a considerar, indiretamente, o professor como responsável pela baixa qualidade de ensino, fato que justificaria os baixos salários e as condições de trabalho impostas à categoria (CARDELLI, 1998) ${ }^{3}$.Tais análises geraram um discurso, produzido nas esferas mais altas do poder e reproduzido nas escolas pelos seus representantes, ou por aqueles que exercem poder diretamente sobre a docência: dirigentes, delegados e supervisores de ensino, diretores de escola, coordenadores pedagógicos.

Outros estudiosos analisam de maneira diferente essa mesma questão. Michael Apple (1995), Thomas Tadeu da Silva $a^{4}$ entre outros autores, apontam como causas provocadoras da fragilidade da atuação docente: a proletarização da categoria profissional e a intensificação do trabalho docente, que provocariam um abandono das atividades intelectuais e culturais do professor, bem como a desmobilização dos professores em relação às suas reivindicações trabalhistas. Ainda, Francisco Imbernón (2002) analisa 0 professor na

\footnotetext{
2 POPKEWITZ, Gubernamentalidad y formación docente. In: BIRGIN, A. et alli. La formación docente: cultura, escuela y política. Debates y experiencias. Buenos Aires (Arg.): Troquel Educación, 1998, p. 6772 (Serie FLACSO Acción), p. 55-66.

3 CARIJELLI, J. Elementos de la dinâmica de poder en la atual reforma educativa. In: BIRGIN, A. et alli (comp.). In: BIRGIN, A. et alli. Op. cit., p. 55-66.

4 APPLE, M. W. Trabalho docente e textos: economia política das relações de classe e gênero em educação. Porto Alegre: Artes Médicas, 1995 e SILVA, T.T. Educación poscrítica, curriculum y formación docente . Birgin, A. et alii (comp.) - Op. cit., p. 21-34
} 
perspectiva da sua profissionalização e dos perigos representados pela proletarização. ${ }^{5}$

Exige-se, então, do professor que construa uma nova identidade profissional, o que somente poderá ocorrer num processo longo e complexo, freqüentemente imperceptível para o sujeito. A nova identidade profissional, que se cobra do professor, corresponde às expectativas que o sistema mantém em relação à aceitação das reformas educacionais. Desconsidera-se que a auto-estima é um dos componentes da identidade pessoal e profissional: ela se constrói e reconstrói de modo mais ou menos consciente por cada um ao longo de seu itinerário. Quem sou e para que eu sirvo? Os sentimentos, as representações de si mesmo ligadas a essas questões aparecem quando as pessoas falam de suas práticas profissionais, de suas histórias, de suas idéias de excelência na sua profissão. Isto será definido por atitudes profissionais, ao fim de um certo tempo, e concebido como respostas aos acontecimentos aleatórios do cotidiano, de rotinas eficazes, como uma capacidade de se adaptar, como reconhecimento da complexidade das situações educativas cotidianas. A imagem de si tem a ver com o sentimento de legitimidade (CAUTERMAN et allii, 1999) ${ }^{6}$.

Ao mesmo tempo, há uma identidade profissional, também construída, que responde pelas concepções que os professores construíram a respeito de si mesmos e de seu grupo, matrizes determinadas pela sua posição social, que cria visões de mundo, que levam a determinadas práticas sociais e a julgamentos, políticos, morais estéticos. Essa matriz, que Bourdieu chama de habitus é uma "ambição indispensável para tentar totalizar numa prática realmente cumulativa o conjunto dos saberes e do saber-fazer acumulados em todos os atos de conhecimento no passado e no presente" (BOURDIEU, 2001, p. 64) ${ }^{7}$.

A presença de tais matrizes é evidente nas diferentes pesquisas realizadas entre professores de História nas duas últimas décadas. Trabalhos desenvolvidos por CAMARG0 et alli, (1989/90), ABUD (1999), LORENZI, et allii, (1999), $\mathrm{BASSO},(2000)^{8}$ nos mostram que os professores consideram a História como

\footnotetext{
5 IMBERNÓN, F. La formación y el desarrollo profesional del profesorado: hacia una nueva cultura profesional $5^{\text {a }}$ ed. Barcelona: Graó, 2002. (Biblioteca de Aula, 119)

6 CAUTERMAN, M.M. et allii. La formation continue des enseignants est-elle utile? Paris: Presse Universitaire de France, 1999.

7 BourdieU, P. O poder simbólico. $4^{\mathrm{a}}$ ed. Rio de Janeiro: Bertrand Brasil, 2001.
} 
uma disciplina essencialmente formativa, que prepara os alunos para o exercício da cidadania e para a atuação como agente transformador da sociedade. Há uma rejeição explícita, na fala dos docentes, à história factual, a que valoriza os grandes personagens e a datação. Por outro lado, indicam também a importância de determinados conceitos para aprendizagem de História conceitos como tempo/espaço, trabalho, relações sociais, entre outros, são considerados fundamentais para o desenvolvimento de seu trabalho. Em relação a métodos de ensino, aprovam e a grande maioria afirma utilizar, diferentes materiais didáticos como documentos de época, textos, mapas, ilustrações, livros paradidáticos, além das inovações tecnológicas como cinema, internet e a informática em geral. Os professores de História, ainda manifestam sua rejeição por aulas expositivas, nas quais exercem 0 poder que lhes confere 0 saber e declaram sua aprovação às aulas que contam com a participação efetiva dos alunos, seja em debates, trabalhos em grupos e outras formas participativas de organização das aulas.

Camargo, Zamboni e Galzerani enfocam as concepções dos professores de História, na perspectiva das correntes de pensamento dominantes e ao analisar as respostas dos professores de História ás questões que lhes foram colocadas, percebem que "os professores estão em processo pessoal de transformação que os impossibilita de declinarem suas concepções sobre história. Implicitamente há um descrédito das concepções fechadas e absolutas da história como também certo desânimo que pode implicar em imobilização. Nota-se positivamente a constatação de que verdades absolutas não ajudam avançar. 0 mesmo enfoque é retomado por Basso (2000), que remete a questão para a formação docente e para a prática pedagógica que se fundamenta na concepção de História do professor e na sua metodologia de investigação histórica. Dessa

8 CAMARGO, D.M.P, ZAMBONI, E. e GAlZERANi, M. C. B. Sabor e dissabores do Ensino de História. Revista Brasileira de História. São Paulo: v. 9, n 19, pp. 181-195, set. 89/fev. 90; ABUD, K. M. Professor, professores: um perfil dos professores de História da rede estadual paulista. Comunicação apresentada ao IX ENDIPE, Águas de Lyndóia, 1998 (texto digitado); LORENZI, M. G. R., CEZNE, A. N., MONTAGNER, R.; CUNHA, J. L. Concepções do ensino de História no processo de formação. In: SCHMIDT, M.A. e CAINELLI, M. III Encontro Perspectivas do Ensino de História. Curitiba: Aos quatro ventos, 1999, p. 67-75; BASSO, I. S. As concepções de História como mediadoras da prática pedagógica do professor de História. Didática. São Paulo, n. 25, p. 110, 1989. Veja-se também versão revista do mesmo artigo In: DAVIES, N. (org). Para além dos conteúdos do ensino de História. Niterói: EdUFF, 2000, p. 45-60. 
forma, segundo a autora, a articulação entre o que se ensina (conteúdo) e como se ensina (metodologia de ensino) se realiza pela mediação de uma concepção de História que reflete uma certa concepção de mundo, que decorre da "formação que esse professor recebe na universidade - orientação positivista ou orientações mais críticas" que "influencia sua atuação em sala de aula, ensinando uma história factual e cronológica ou uma história que permita apreender a historicidade da realidade social."

Embora as pesquisas tenham sido realizadas há mais de uma década, a concepção que considera a formação das ciências de referência como o exclusivo pilar sobre qual se assenta o trabalho pedagógico, é ainda muito freqüente. Participantes desse mesmo debate, em geral professores dos cursos de graduação das áreas de conhecimento, manifestando-se em encontros de associações científicas, enfatizam a qualidade de ensino dos cursos ministrados pelas universidades que mantém projetos de pesquisa, em geral representadas por universidades públicas e poucas particulares. A elas contrapõem a formação ministrada nos cursos superiores de instituições de caráter privado, nos quais pouca ou nenhuma importância se dá à pesquisa e à produção do conhecimento.

As universidades que produzem pesquisas são as mais prestigiadas também no universo dos professores do ensino fundamental e médio. Os diplomas por elas emitidos são garantia para empregos em escolas particulares, nas quais, se acredita, o valor da hora aula é maior e as condições de trabalho e a infra-estrutura material são melhores que nas escolas públicas. Por outro lado, os grandes nomes da historiografia são também docentes nas instituições produtoras de pesquisa, que se constituem em modelo de formação. E nelas, procuram se espelhar os mestres da escola básica, construindo a partir daí 0 habitus do grupo, seguindo as trilhas desse grupo dominante.

$\mathrm{Na}$ pesquisa realizada por ABUD (1999) com professores de escolas de três Delegacias de Ensino da rede pública estadual, na zona sul da cidade de São Paulo, houve manifestações de desagrado, porque entre as diferentes concepções de História pelas quais poderiam optar, havia algumas que poderiam ser consideradas positivistas. Pareceu-lhes ofensivo, que a pesquisa considerasse possível que algum deles optasse por assinalar a afirmação que a "História é um encadeamento de fatos, realizados por heróis." Num dos questionários, o entrevistado anotou que se estava "subestimando a inteligência 
do professor.", por que os professores sabiam que aquela concepção era "errada". (ABUD, 1999).

Tomando as pesquisas citadas acima como fundamento, pode-se concluir que os professores de História da rede estadual de São Paulo estão sintonizados com as novas tendências da historiografia, rejeitando o ensino da disciplina que se organiza de acordo com os cânones do que se convencionou chamar de "História Positivista": conteúdos seqüenciais, arrolados pela cronologia, com predominância de fatos políticos e valorização de sujeitos individuais, responsáveis pela realização daqueles.

Contudo, os relatos orais e escritos de estagiários de Metodologia de Ensino de História I e II, da Faculdade de Educação da Universidade de São Paulo, apontam que em sala de aula, a maioria dos professores segue em direções diferentes das que valorizam, desenvolvendo seu trabalho pedagógico com poucas inovações no se refere à organização dos conteúdos e aos métodos de ensino. As narrativas dos alunos sobre 0 contato direto que, durante 0 estágio, mantém com alunos e professores de História, provocam algumas inquietações que nos levam a perguntar até que ponto se cruzam a auto imagem dos professores, construída a partir de um campo dominante, o acadêmico, e o cotidiano na sala de aula.

Reconhecendo que a "aula de História é o momento em que, ciente do conhecimento que possui, o professor pode oferecer a seu aluno a apropriação do conhecimento histórico existente, através de um esforço e de uma atividade com a qual ele retome a atividade que edificou esse conhecimento (SCHMIDT, 1997)" ${ }^{10}$, a percepção dos futuros professores traz novos elementos para a compreensão do que ocorre com o ensino de História. Para essa finalidade foram analisados 7 relatórios de 2001, 16 relatórios de 2002 e 12 de 2002, perfazendo total de 32 relatórios. Os relatórios selecionados são os que narram estágio no Ensino Médio, da rede estadual, que concentra as escolas daquele grau. Adotou-se esse critério por que as pesquisas anteriores tinham recaído sobre os professores de História da rede estadual.

A maioria dos professores que recebiam os estagiários $(56,25 \%)$ tinha

\footnotetext{
9 ABUD, K. M. op. cit.

${ }^{10}$ SCHIMIDT, M. A. A formação do professor de História e o cotidiano da sala de aula. IN: BITTENCOURT, C. O saber histórico em sala de aula. São Paulo: Contexto, 1997, p. 54-66.
} 
mais que 10 anos de trabalho na rede pública escolar, fato compreensível, se se considerar que 0 tempo de serviço eleva a classificação do professor para a escolha das classes e que é nítida entre eles a preferência pelas turmas mais avançadas, como as do ensino médio. 0 fato ainda de a pesquisa se ater ao ensino médio explica a divisão igual entre professoras e professores: do grupo de trinta e dois professores, dezesseis professores de cada sexo, quando num quadro geral de escolas de ensino fundamental e médio, pode-se observar que numericamente as professoras são predominantes. No ensino médio, a faixa etária dos alunos é mais alta e nele se concentra a ocorrência dos principais problemas que afetam as escolas, como tráfico, violência, a atuação de gangs. Outro aspecto que deve ser lembrado e que afastaria, por insegurança, as ' professoras é a localização das escolas públicas, cuja grande maioria se situa em bairros periféricos, considerados como regiões de alta periculosidade.

Os professores foram agrupados por suas instituições de origem, pois nos interessava confirmar, mediante as representações dos estagiários, algumas afirmações quanto à importância da instituição formadora e das atividades de pesquisa, já referidas acima. Os professores se formaram em diferentes instituições de ensino, conforme se pode observar do quadro abaixo:

Quadro 1 - Formação de professores quanto a instituição - 2001/2003

\begin{tabular}{|c|l|l|l|l|l|}
\hline & 2001 & 2002 & 2003 & \multicolumn{2}{|l|}{ Total } \\
\hline USP: & 4 & 3 & 3 & 10 & $31,25 \%$ \\
\hline PUC/SP & 2 & 6 & 2 & 10 & $31,25 \%$ \\
\hline $\begin{array}{c}\text { Outras faculdades } \\
\text { particulares*: }\end{array}$ & 1 & 7 & 4 & 12 & $37,50 \%$ \\
\hline
\end{tabular}

*UNISA, FAI, FMU, UNIP, UNISANTOS, Faculdades Teresa Martin, Universidade São Marcos.

Os cursos de História da USP e da PUC-SP desenvolvem, reconhecidamente, projetos de pesquisa com os alunos de Graduação e há planos de carreira e exigência do desenvolvimento de pesquisa pelos docentes e participação dos alunos de graduação. A distinção entre os cursos de origem dos professores pareceu-nos um elemento importante para este trabalho, por se pretender estabelecer a relação entre a formação e a atuação em sala de aula.

Apareceram nos relatórios, como categorias de análise: organização de conteúdos; metodologia de ensino; relacionamento com os alunos e objetivos 
do ensino de História. Tais categorias estão presentes em todos os relatórios, expressas de forma diferenciada, mas recorrente. Neste trabalho nos deteremos na organização dos conteúdos e na metodologia utilizada predominantemente pelos professores.

A questão da organização dos conteúdos expressa, tanto quanto a postura do professor, inseguranças dos estagiários quanto às inovações curriculares, como a introdução dos eixos temáticos no ensino de História. Em 1993, foi publicada a Proposta Curricular para 0 ensino de História $-2^{\circ}$ grau, que ao introduzir a organização dos conteúdos por eixos temáticos, procurava implementar na escola média temas inovadores, de acordo com as mais recentes tendências historiográficas e quebrar dessa maneira, a hegemonia da História Política, estruturada unicamente por meio da cronologia e da periodização clássica. No contexto em que foi implementada, quando se criaram, no estado de São Paulo, as escolas-padrão e se expandiam os cursos para professores, a proposta se difundiu e juntamente com a de primeiro grau, que também propunha os eixos temáticos, propiciou a discussão e 0 trabalho pedagógico com base nos novos paradigmas. Com a extinção das escolas-padrão, poucas instituições publicas que mantém ensino básico mantiveram a proposta do ensino temático, mesmo reforçada, em outras bases, com a publicação dos Parâmetros Curriculoares Ns. 0 ensino organizado por meios dos eixos temáticos é considerado difícil, pela maioria dos professores, pois exige constantes leituras e elaboração para ser posto em prática, mas ainda permanece em algumas escolas.

Desenvolver o curso de História pelo ensino temático auxilia o professor a introduzir novos temas e novas abordagens em sala de aula e de certa forma garantiria escapar do ensino "tradicional", da história seqüencial e da cronologia, todos elementos rejeitados pelos professores em suas falas e resposta a entrevistas. Donde poder-se-ia supor que fosse a opção predominante entre eles, principalmente entre os egressos das universidades onde se exerce a pesquisa. No entanto, as informações contidas nos relatórios mostram que a História organizada de forma cronológica e sequiencial ainda é a preferida dos professores, quelquer que seja sua origem universitária, conforme pode-se observar no quadro abaixo: 
Quadro 2 - Preferenuids por forma de organização de conteúdos

\begin{tabular}{|l|l|l|l|l|l|l|l|l|}
\hline USP & Linear/cronológica & 6 & $18.75 \%$ & $60 \%$ & Temática & 4 & $12.50 \%$ & $40 \%$ \\
\hline PUC & Linear/cronológica & 6 & $18.75 \%$ & $60 \%$ & Temática & 4 & $12.50 \%$ & $40 \%$ \\
\hline Particulares & Linear/cronológica & 11 & $34.37 \%$ & $91.16 \%$ & Temática & 1 & $03.12 \%$ & $8.3 \%$ \\
\hline
\end{tabular}

Algumas observações podem ser feitas a partir da leitura do quadro:

- Embora entre os professores formados pela USP e pela PUC predomine a opção pela organização dos conteúdos da maneira tradicional, entre eles também se encontra o maior número dos que optaram pelo ensino temático.

- Entre os professores licenciados pelas instituições particulares somente um fez opção pela História temática, segundo o estagiário. Contudo, uma listagem dos conteúdos indica que se desenvolve o que se chama hoje de "História integrada", isto é intercalam-se capítulos de História Geral e do Brasil, sobre temas temporalmente coincidentes. (Relatório A, 2003).

Quanto aos métodos e técnicas de ensino, os relatórios apontam a predominância entre das aulas expositivas entre o grupo dos professores egressos da USP. Cinco deles (50\%) ministram aulas expositivas simplesmente, enquanto a outra metade ilustra suas aulas com materiais didáticos, predominando a utilização de jornais e revistas, seguida do uso de imagens fixas. Somente um professor desse grupo utilizou filmes e um organiza seminários, que intercala com as aulas expositivas. Entre os professores egressos da PUC, três ministram aulas expositivas, sem auxílio de material, outros três utilizam imagens. Devese ressaltar, em favor dos professores que ministram esse tipo de aula, que se empenham em provocar a participação dos alunos, com perguntas a serem respondidas oralmente. 0 mesmo não acontece com os quatro professores licenciados pelas faculdades particulares, cujas aulas expositivas são dominadas por eles, que se dirigem a pequenos grupos de alunos, que prestam atenção. ${ }^{11}$

No grupo dos professores formados por escolas particulares predominam as aulas na quais o aluno copia da lousa, recebe ditado do professor ou recebe a cópia xerográfica de um texto que deve ler, e algumas vezes realizar atividades

\footnotetext{
${ }^{11}$ A restrição ao grupo de alunos que presta atenção se deve ao fato de a indisciplina e o barulho serem permanentes durante as aulas, de modo que os próprios estagiários ao relatarem suas experiências, o tratam como natural e normal.
} 
depois da leitura. São sete os professores que desenvolvem seu trabalho dessa maneira. Este tipo de aula não conta com o apoio dos estagiários, pois consideram uma maneira de isenção da responsabilidade do professor, e ao mesmo uma demonstração de fragilidade teórica, conforme um dos relatos: “...às vezes tenho a sensação que ele não a prepara (a aula), por que pede aos alunos para fazerem um resumo do capítulo a ser estudado, na outra aula pede voluntários para a leitura do capítulo (para que, se os alunos já leram em casa?). ...pede para fazerem os exercícios da apostila e (depois) os corrige e dá nota. Será que é preciso repetir esse tipo de aula todas as vezes? ...será que não há outros meios mais interessantes para se dar um conteúdo?" (Relatório C, 2001).

$\mathrm{Na}$ atuação em sala de aula se encontra outro fator de diferenciação entre os professores das universidades com tradição de pesquisa e os originários de instituições universitárias constituídas em período mais recente. Diante das informações sobre os objetivos elucidados pela observação em sala de aula e sobre o relacionamento com os alunos, pode-se perceber a relação entre os três elementos. A formação pedagógica não é um dos pontos fortes da formação do professor. Ao contrário, vista como uma questão secundária, é o campo menos discutido pelas instituições de ensino superior, e visto mais como uma complementação que um conjunto de saberes integrados à formação profissional. É de se notar que a continuidade e permanência do que poderíamos chamar de "conteúdos tradicionais" da História escolar se alia a permanências da metodologia de ensino. 0 binômio História cronológica mais aula expositiva, é pois, privilegiado pelos professores egressos de universidades que mantém projetos de pesquisas de reconhecido valor.

A existência de conteúdos e práticas conservadoras não indica, porém, que se possa traçar uma trajetória linear para o ensino de História, pois este se se desenvolve por meio de processos contraditórios. Os processos de afirmação da autonomia e da profissão docente ganharam ímpeto, no início dạ década passada, com reformas educacionais, projetos de renovação, cursos e reuniões que mobilizavam os professores. As transformaç̧ões ocorridas nos últimos oito anos e as políticas públicas implementadas no estado de São Paulo nesse período, com raros momentos de enconîros entre professores do ensino 
fundamental, principalmente ${ }^{12}$ os afastaram das discussões sobre sua atividade profissional. Esta é uma das hipóteses que auxiliariam a compreensão do conservadorismo no ensino. Outra hipótese que poderia ser colocada diz respeito ao cotidiano. 0 cotidiano escolar em suas cadeias de relações e hierarquização idealiza o professor como aquele que sabe utilizar técnicas e métodos de ensino, e como o que domina o saber acadêmico que lhe dá suporte no trabalho de sua transformação em saber escolar. A demonstração delas demanda uma continuidade deste trabalho, pois outros elementos, que não se fazem presentes nos relatórios dos estagiários devem contribuir para a elucidação dessas questões.

0 quadro abaixo sintetiza os modos de se trabalhar em sala de aula, utilizados pelos professores:

Quadro 3 - Formas de trabalho em sala de aula

\begin{tabular}{|l|l|l|l|l|l|l|}
\hline & \multicolumn{2}{|c|}{ USP } & \multicolumn{2}{c|}{ PUC } & \multicolumn{2}{c|}{ Outras } \\
\hline Aula expositiva - & 5 & & 3 & & 4 & \\
\hline Seminários & 1 & & & & & \\
\hline Aula interativa & & & & & & \\
\hline $\begin{array}{l}\text { Leitura/cópia/ditado/questionário (grupos ou } \\
\text { individualmente) de l. d. ou apostilas. }\end{array}$ & 1 & & 5 & & 7 & \\
\hline Utilização de diferentes materiais didáticos & 6 & & 2 & & 2 & \\
\hline Saídas & & & & & & \\
\hline
\end{tabular}

${ }^{12}$ Neste segundo semestre, a Secretaria da Educação descentralizou as atividades de formação continuada, transferindo-as para as diretorias de ensino (antigas delegacias de ensino), num projeto denominado Teia do Saber. Algumas delas já deram início às atividades, incluindo nelas os professores de ensino médio. 


\section{Bibliografia}

ABUD, K. M. Professor, professores: um perfil dos professores de História da rede estadual paulista. Comunicação apresentada ao IX ENDIPE, Águas de Lyndóia, 1998 (texto digitado).

APPLE, M. W. Trabalho docente e textos: economia política das relações de classe $e$ gênero em educação. Porto Alegre: Artes Médicas, 1995.

BARCA, I. A educação histórica na sociedade de informação. 0 Ensino de História. Publicação Quadrimensal. Boletim da APH, n. 19/20, p. 35-42, fev. jun. 2001.

BASSO, I. S. As concepções de História como mediadoras da prática pedagógica do professor de História. Didática. São Paulo, n. 25, p. 1-10, 1989. Veja-se também versão revista do mesmo artigo In: DAVIES, N. (org). Para além dos conteúdos do ensino de História. Niterói: EdUFF, 2000, p. 45-60.

BOURDIEU, P. O poder simbólico. 4a ed. Rio de Janeiro: Bertrand Brasil, 2001.

CAMARGO, D.M.P, ZAMBONI, E. e GALZERANI, M. C. B. Sabor e dissabores do Ensino de História. Revista Brasileira de História. São Paulo: v. 9, nº 19, pp. 181-195, set. 89/fev. 90.

CAUTERMAN, M.M. et allii. La formation continue des enseignants est-elle utile? Paris: Presse Universitaire de France, 1999.

IMBERNÓN, F. La formación y el desarrollo profesional del profesorado: hacia una nueva cultura profesional $5^{a}$ ed. Barcelona: Graó, 2002. (Biblioteca de Aula, 119)

LEE, Peter. Walking backward into tomorrow. Historical conscieousness understanding history. History in education. Unit School of Arts and Humanities. University of London Institute of Education. Paper given at Annual Meeting of American Research Association, New Orleans. 2002.

LORENZI, M. G. R., CEZNE, A. N., MONTAGNER, R.; CUNHA, J. L. Concepções do ensino de História no processo de formação. In: SCHMIDT, M.A. e CAINELLI, M. III Encontro Perspectivas do Ensino de História. Curitiba: Aos quatro ventos, 1999, p. 67-75.

POPKEWITZ, Gubernamentalidad y formación docente. In: BIRGIN, A. et alli. La formación docente: cultura, escuela y política. Debates y experiencias. Buenos Aires (Arg.): Troquel Educación, 1998, p. 67-72 (Serie FLACSO Acción), p. 55-66.

SCHIMIDT, M. A. A formação do professor de História e o cotidiano da sala de aula. IN: BITTENCOURT, C. O saber histórico em sala de aula. São Paulo: Contexto, 1997, p. 54-66. 


\section{The curricular construction in the classroom}

\section{ABSTRACT}

The reports made by the trainees of Methodology of History Teaching discipline bring information about the classroom and the performance of the teachers that receive them. Such information allows realizing how the teachers elaborate their own curriculum, elaborating contents and teaching methods that evade from that indicated by the responsible public organs for the education area. When distinguishing the performance of the teachers whose formation took place in institutions of different characters, the reports are an important source for analyzing the force that the formation has.

Key-words: History Teaching, Probation, teachers' formation 